\title{
MEASUREMENT AND INHERITANCE OF ENVIRONMENTAL RESPONSE AMONGST SELECTED MATERIAL OF LOLIUM PERENNE
}

\author{
J. HILL and C. J. A. SAMUEL* \\ Welsh Plant Breeding Station, Aberystwyth
}

Received 14.x.70

\section{INTRODUCTION}

GENOTYPE-ENVIRONMENT interactions have impeded progress towards a fuller understanding of the control of genetic variation for some time past. However, techniques have now been developed which are capable of placing these interactions upon a more rational and hence predictable footing.

Prior to such developments the principal analytical approach to these problems had been to estimate the various genotype-environment interaction components from an analysis of variance (see Comstock and Robinson, 1952; Hanson, Robinson and Comstock, 1956). These estimates were then used to identify those environmental factors which interacted most strongly with genotypes, so that subsequent experiments could be modified accordingly. However, this approach necessarily demands a large number of replicates within each environment in order to obtain accurate estimates of the environmental means. Consequently, the amount of progress attainable solely by this approach is limited chiefly by practical considerations. Thus, far from solving the problems posed by such interactions, this approach has instead created an impasse.

Recently, interest has centred upon regression techniques as an alternative method of analysing genotype-environment interactions. Suggested originally by Yates and Cochran in 1938, these techniques have been employed and modified by numerous workers using a wide range of plant material (see Finlay and Wilkinson, 1963; Eberhart and Russell, 1966; Bucio Alanis, 1966; Bucio Alanis and Hill, 1966; Perkins and Jinks, 1968a, $b$; Breese, 1969; Samuel, Hill, Breese and Davies, 1970). In contrast to the analysis of variance this approach attaches greater importance to a wide coverage of the environmental range even though this may entail the loss of some information on replicate errors within each environment.

The present article describes an experiment wherein these regression techniques have been employed in the analysis of a diallel cross between some of the mother plants upon which the S.24 cultivar of perennial ryegrass (Lolium perenne) was founded, the object being not merely to measure but also to determine the inheritance of environmental response in this material.

It should be pointed out that, although exotic (New Zealand) genotypes constituted half the sample of parents ultimately used in this experiment, S. 24 is in fact based largely upon indigenous material (see Jenkin, 1943, for details).

* Present address: Forest Research Station, Alice Holt Lodge, Wrecclesham, Farnham, Surrey. 


\section{THE EXPERIMENT}

Initially 10 genotypes were intercrossed in all combinations, but insufficient seed was obtained from some of the crosses to enable the experiment to be carried out as originally intended. Consequently the experiment had to be reduced in size to a $6 \times 6$ diallel cross without selfs. Of these six parents, half were of New Zealand origin whilst the remaining three were derived from indigenous material. The 30 families resulting from this diallel cross may be classified, therefore, into three groups: first, a group of six families whose parents originated from New Zealand; second, a further group of six families both of whose parents were of indigenous origin, and third, a group of 18 families of mixed descent.

This material was sown in pots containing a standard compost mixture. Normally two seeds were sown per pot, although these were later thinned to leave the plant nearest the centre of each pot. At this stage the material

TABLE 1

Levels of fertiliser applied ( $\mathrm{kg} . / \mathrm{ha}$.

\begin{tabular}{|c|c|c|c|c|}
\hline Season & & 68 & & 69 \\
\hline Nutrient & Low Nitrogen & High Nitrogen & Low Nitrogen & High Nitrogen \\
\hline Nitrogen & 60 & 1063 & 90 & 843 \\
\hline Phosphorous & 60 & 60 & 90 & 90 \\
\hline Potassium & 90 & 90 & 135 & 135 \\
\hline
\end{tabular}

was arranged in two blocks. However, as will be seen later, these blocks are not replicates in the strict statistical sense. All families were represented by 10 plants per block, while each block was randomised at the individual plant level. The initial phases of this experiment were conducted in a glasshouse during the early spring of 1968. Subsequently the material was transferred to the experimental area where it was square planted at $30 \mathrm{~cm}$. intervals. The experiment was surrounded by a single row of guards, though the adjacent blocks were separated by a double row to reduce the passage of nutrients between them. At monthly intervals throughout the growing seasons of 1968 and 1969 all plants were cut to a uniform height and their fresh weight recorded in grams. After each cut the whole experimental area received a basal dressing of complete fertiliser, whilst additional nitrogen was supplied to one of the two blocks of plants designated the high nitrogen treatment. Details of these fertiliser treatments are furnished in table 1 .

\section{Results}

\section{(a) Analysis of variance and phenotypic regressions}

Mean annual yields of all 30 families are presented in table 2, whilst an analysis of the full results, given in table 3 , indicates that the families differ significantly amongst themselves for this character. Furthermore, it would appear that these differences can be related partly to the geographic origin of the parents, since the indigenous parents give rise to families which outyield the New Zealand material, whilst families of mixed descent are on average 
slightly above the midparent value in terms of annual production. Further points also emerge from this analysis, particularly the pronounced effect of

TABLE 2

Mean fresh weight values for the 30 families averaged over nitrogen levels and years

\begin{tabular}{|c|c|c|c|c|c|c|c|c|}
\hline & & & & Male & & & & \\
\hline $\begin{array}{l}\text { Array } \\
\text { No.* }\end{array}$ & 1 & 2 & 3 & 4 & 5 & 6 & Mean & $\begin{array}{c}\text { Parental } \\
\text { origin }\end{array}$ \\
\hline C (23) & - & $325 \cdot 8$ & $229 \cdot 4$ & $288 \cdot 0$ & $279 \cdot 9$ & $276 \cdot 6$ & $279 \cdot 9$ & New Zealand \\
\hline $2(24)$ & $332 \cdot 4$ & - & $314 \cdot 4$ & $349 \cdot 8$ & $411 \cdot 5$ & $319 \cdot 7$ & $345 \cdot 6$ & Indigenous \\
\hline $3(36)$ & $254 \cdot 1$ & $320 \cdot 5$ & - & $293 \cdot 2$ & $275 \cdot 8$ & $281 \cdot 0$ & $284 \cdot 9$ & Indigenous \\
\hline $4(85)$ & $270 \cdot 7$ & $367 \cdot 9$ & $323 \cdot 6$ & - & $366 \cdot 7$ & $248 \cdot 8$ & $315 \cdot 5$ & New Zealand \\
\hline $5(96)$ & $311 \cdot 4$ & $431 \cdot 8$ & $258 \cdot 3$ & $363 \cdot 8$ & - & $341 \cdot 9$ & $341 \cdot 4$ & Indigenous \\
\hline $6(131)$ & $251 \cdot 4$ & $338 \cdot 4$ & $212 \cdot 5$ & $281 \cdot 7$ & $354 \cdot 1$ & - & $287 \cdot 6$ & New Zealand \\
\hline Mean & $284 \cdot 0$ & $356 \cdot 9$ & 267.6 & $315 \cdot 3$ & $337 \cdot 6$ & $293 \cdot 6$ & $309 \cdot 2$ & \\
\hline
\end{tabular}

* Figures in parentheses indicate W.P.B.S. reference number.

Mean annual yield of six families derived from New Zealand parents $=269.5$

Mean annual yield of six families derived from indigenous parents $=335.4$

Mean annual yield of 18 families of mixed descent $=313.7$

TABLE 3

Analysis of variance of mean fresh weight data

Item d.f. M.S.

Environments (E):

$\begin{array}{rlrc}\text { (i) } & \text { Years (Y) } & 1 & 93,813 \cdot 0 \\ \text { (ii) } & \text { Nitrogen levels (N) } & 1 & 287,886 \cdot 0 * * * \\ \text { (iii) } & \mathrm{Y} \times \mathrm{N} & 1 & 67,542 \cdot 3 * * * \\ \text { (iv) } & \text { Cuts within Y(CwY) } & 12 & 35,795 \cdot 2 \\ \text { (v) } & \mathrm{N} \times \mathrm{CwY} & 12 & 20,321 \cdot 8 * * * \\ \text { (vi) Families (F) } & \text { (a) Between groups } & 2 & 3,975 \cdot 0 \dagger \\ & \text { (b) Between families } & 27 & 1,339 \cdot 9 * * \\ & \text { within groups } & \end{array}$

$\mathrm{F} \times \mathrm{E}:$

\begin{tabular}{|c|c|c|c|c|}
\hline (vii) & $\mathbf{F} \times \mathbf{Y}$ & 29 & $127 \cdot 7$ & Heterogeneity \\
\hline (viii) & $\mathbf{F} \times \mathrm{N}$ & 29 & $513 \cdot 4 * *$ & of linear \\
\hline$(\mathrm{ix})$ & $\mathbf{F} \times \mathbf{Y} \times \mathbf{N}$ & 29 & $219 \cdot 7 * * *$ & regressions (29) \\
\hline$(\mathrm{x})$ & $\mathrm{F} \times \mathrm{CwY}$ & 348 & $65 \cdot 5 *$ & $1249 \cdot 6 * * *$ \\
\hline (xi) & $\mathrm{F} \times \mathrm{N} \times \mathrm{CwY}$ & 348 & $50 \cdot 8$ & Residual (754) $38 \cdot 7$ \\
\hline$(x \mathrm{xi})$ & $\begin{array}{l}\text { Within families, within } \\
\text { environments (error) }\end{array}$ & 7107 & $52 \cdot 0$ & \\
\hline
\end{tabular}

Throughout all tables $+\mathrm{P}=0 \cdot 10-0.05 ; * \mathrm{P}=0.05-0.01 ; * * \mathrm{P}=0.01-0.001 ; * * *$ $P=<0.001$.

Items (i and ii) have been tested against item (iii)

Items (iii, vii and viii) have been tested against item (ix)

Item (via) has been tested against item (vi $b$ )

Item (vib) has been tested against item (viii)

Items ( $v$ and $x$ ) have been tested against item ( $x i)$

Item (iv) has been tested against item (v)

Items (ix and $x i$ ) have been tested against item (xii)

nitrogen upon yield. But in the present context the most important feature is undoubtedly the inconsistent behaviour of the families across the range of environments encompassed by this experiment, as shown by the significant 
interactions between families and nitrogen levels on the one hand and families and cuts within seasons on the other. In order to examine these interactions in greater detail recourse has been made, therefore, to the regression techniques referred to earlier.

Since it is apparent from table 3 that considerable differences exist between the 28 cuts obtained over seasons and nitrogen levels, each cut has been regarded as a distinct environment for the purposes of this analysis. From the regression analysis, also presented in table 3 , it is evident that a highly significant proportion of the families $\times$ environments interaction can be ascribed to heterogeneity between the linear regression slopes of the 30 families. Furthermore, the residual item, which measures the deviations of each family about its own regression line pooled over all families, is not significant when tested against the experimental error. It should be pointed out here that in order to obtain an estimate of error appropriate for testing differences between family means the variation between plants accumulated over families and environments has been divided by the harmonic mean of the number of plants surviving within each family in all 28 environments. Because of the heterozygous nature of the material such an error will of course contain both genetic sampling and environmental components of variation. This estimate of error is not entirely satisfactory, however, since the variances within the high nitrogen treatment are larger than those within the low nitrogen treatment. Even so, the correlation between mean yield and variance is by no means absolute so that a transformation of the data was not thought necessary. Thus at this juncture there is no reason for supposing that the response of these families over the complete range of environments which they experience in this experiment is anything but linear.

At this stage it is necessary to consider further the form of analysis presented in table 3. Freeman and Perkins (1971) criticise on statistical grounds the use of the mean of all varieties as an estimate of the environment, and advocate the use of independent assessment of each environment by the use of controls. These might be standard varieties or extra replicates of the material under study. For reasons already advanced, replicates in the strict statistical sense were not employed here, nor may any of the six genotypes included in this experiment be regarded as a control. It is, therefore, not possible to adopt the qualifications proposed by these authors in this experiment. The absence of such independent assessment may lead to some imprecision in attaching errors to the response regressions and biases in the regression coefficients themselves, but the effect of these is unlikely to be serious in a large experiment involving many genotypes.

\section{(b) Correlation between mean and regression slope}

Inspection of tables 2 and 4 discloses a striking similarity in the ranking of arrays for both mean and response which is indicative of a positive correlation between these two phenotypic components. This is amply confirmed at the family level where there is an overall correlation of $0 \cdot 876^{* * *}$. The presence of such a high correlation signifies that the genotype-environment interactions in this material are of the non-crossover type, whilst a positive correlation implies that family differences will increase as the environment improves. Of the six parental genotypes represented here 2, 4 and 5 would, 
by virtue of their greater sensitivity to environmental change, appear to be adapted to more favourable environments, whereas the remaining genotypes are suited to less favourable conditions. Finlay and Wilkinson (loc. cit.) have likewise employed these parameters to characterise the type of environment to which a particular genotype is adapted. However, they have also used the regression coefficient as a definition of phenotypic stability. In the present context this is perhaps misleading since stability should be more properly reserved to measure the deviations of a genotype about its own regression

TABLE 4

Overall $\mathrm{b}$ values of the 30 families

$\begin{array}{cccccccc}\text { Array } & 1 & 2 & 3 & 4 & 5 & 6 & \text { Mean } \\ 1 & - & 1.035 & 0.630 & 1.047 & 0.875 & 0.961 & 0.910 \\ 2 & 1.115 & - & 0.857 & 1.115 & 1.308 & 1.023 & 1.084 \\ 3 & 0.750 & 1.086 & - & 0.944 & 0.953 & 0.825 & 0.912 \\ 4 & 0.973 & 1.184 & 0.993 & - & 1.290 & 0.948 & 1.078 \\ 5 & 1.097 & 1.237 & 0.737 & 1.265 & - & 1.050 & 1.077 \\ 6 & 0.740 & 1.175 & 0.647 & 1.084 & 1.056 & - & 0.950 \\ \text { Mean } & 0.935 & 1.143 & 0.773 & 1.091 & 1.096 & 0.961 & 1.000\end{array}$

line as described by Eberhart and Russell (loc. cit.), Hill and Perkins (1969) and Breese (loc. cit.). For predictive purposes as well this latter definition would be more meaningful, since a stable genotype is necessarily one whose performance can be predicted accurately.

\section{(i) Seasonal yield}

\section{(c) Genetic analysis}

Because of the mating design adopted here these data are amenable to the genetic analysis of reciprocal sums and differences proposed by Yates (1947). Basically the total variation amongst families may be partitioned into four items: firstly, variation between parents summed over male and female arrays; secondly, variation between reciprocal sums which remains after allowing for the average effects of parents; thirdly, variation attributable to differences between male and female arrays, and fourthly, variation amongst reciprocal crosses not ascribable to differences between male and female parents.

Applying this analysis to the yield data (table 5) establishes that this character is controlled in the main by additive genetic differences between parents, although it is equally apparent that these differences are themselves mediated by environmental factors. There is, however, a suggestion of dominance amongst the genes controlling this character since overall remain$\operatorname{der}(a)$ is approaching significance at the 5 per cent. level of probability when compared to remainder $(b)$, thus indicating that reciprocal crosses are more alike than crosses which involve different parents. Since it has already been demonstrated that the average yield of families derived from crosses between New Zealand and indigenous material exceeds the midparent value, it may be concluded that such dominance as occurs amongst this material is acting in the direction of increased yield. Finally, it is apparent from the analysis that maternal and paternal effects are of no consequence in the inheritance of this character. 
TABLE 5

Genetic analysis of mean fresh weight data

Overall:

Item d.f. M.S.

(a) Diagonal sums:

$\begin{array}{lrc}\text { Parents } & 5 & 6993 \cdot 3 * * \\ \text { Remainder } & 9 & 673 \cdot 0 \dagger \\ \text { Parents } & 5 & 117 \cdot 4 \\ \text { Remainder } & 10 & 251 \cdot 8\end{array}$

Interaction with years $(\mathrm{Y})$ :

(a)

$\begin{array}{lrr}\text { Parents } & 5 & 234 \cdot 2 \\ \text { Remainder } & 9 & 130 \cdot 5 \\ \text { Parents } & 5 & 87 \cdot 6 \\ \text { Remainder } & 10 & 91 \cdot 9\end{array}$

Interaction with nitrogen levels $(\mathrm{N})$ :

(a)

(b)

$\mathrm{Y} \times \mathrm{N}:$

(a)

(b)

Cuts within years $(\mathrm{CwY})$ :

(a)

$\mathrm{CwY} \times \mathrm{N}$ :

(a)

(b)

$\begin{array}{lrc}\text { Parents } & 5 & 2317 \cdot 4 * * * \\ \text { Remainder } & 9 & 172 \cdot 7 \\ \text { Parents } & 5 & 151 \cdot 6 \\ \text { Remainder } & 10 & 99 \cdot 0\end{array}$

$\begin{array}{lrc}\text { Parents } & 5 & 553 \cdot 8 * * \\ \text { Remainder } & 9 & 78 \cdot 7 \\ \text { Parents } & 5 & 148 \cdot 0 \\ \text { Remainder } & 10 & 215 \cdot 5\end{array}$

Remainder

$215 \cdot 5$

$\begin{array}{lrc}\text { Parents } & 60 & 248 \cdot 9 * * * \\ \text { Remainder } & 108 & 29 \cdot 5 \\ \text { Parents } & 60 & 21 \cdot 1 \\ \text { Remainder } & 120 & 28 \cdot 3\end{array}$

Parents

Remainder

$\begin{array}{rl}60 & 162 \cdot 0 * * * \\ 108 & 29 \cdot 5\end{array}$

Parents

Remainder

$60 \quad 19 \cdot 8$

$120 \quad 29 \cdot 8$

TABLE $6 a$

Mean squares from the joint regression analyses across the four environments supplied by years and nitrogen levels

Item d.f. M.S.

Overall regressions

$29685 \cdot 8^{* * *}$

Heterogeneity of regressions across environments $\quad 87 \quad 42 \cdot 6 * *$

Residual

$580 \quad 29 \cdot 1$

TABLE $6 b$

Mean squares from the joint regression analyses within each of the four environments provided by years and nitrogen levels

\begin{tabular}{|c|c|c|c|c|c|}
\hline \multirow[b]{2}{*}{ Item } & \multicolumn{3}{|c|}{1968} & \multicolumn{2}{|c|}{1969} \\
\hline & d.f. & High $N$ & Low $\mathrm{N}$ & High $N$ & Low $\mathrm{N}$ \\
\hline of regressions & $\begin{array}{r}29 \\
145\end{array}$ & $\begin{array}{c}581 \cdot 0 * * * \\
62 \cdot 4\end{array}$ & $\begin{array}{c}13 \cdot 5^{* *} \\
6.9\end{array}$ & $\begin{array}{c}193 \cdot 8 * * * \\
34.7\end{array}$ & $\begin{array}{l}25 \cdot 3 * \\
12 \cdot 4\end{array}$ \\
\hline
\end{tabular}

Heterogeneity of regressions

Residual

145

$62 \cdot 4$

6.9

$34 \cdot 7$

$12 \cdot 4$ 


\section{(ii) Regression slopes}

Thus far the results illustrate the role of regression techniques in quantifying the response of a genotype to environmental change. But, clearly, the ability of a genotype to respond to such changes is itself a character which warrants further attention, because a comprehensive picture of environmental response can be obtained only after the nature and extent of its inheritance has been determined.

Basically the results of table 3 suggest that within the limits of experimental error the yield of each family has a characteristically uniform rate

TABle 7

Genetic analysis of $\mathrm{b}$ values

Overall:

Item

d.f. M.S.

(a) Diagonal sums:

Parents

$0.526^{* *}$

(b) Diagonal differences:

Remainder

Parents

Remainder

0.047

0.014

0.040

Interaction with years $(Y)$ :

(a)

(b)

$\begin{array}{lrl}\text { Parents } & 5 & 0 \cdot 116^{*} \\ \text { Remainder } & 9 & 0.025 \\ \text { Parents } & 5 & 0.003 \\ \text { Remainder } & 10 & 0.021\end{array}$

Interaction with nitrgoen levels $(\mathrm{N})$ :

(a)

Parents

Remainder

Parents

Remainder

$5 \quad 0.094 * *$

90.014

$5 \quad 0.020$

$\mathrm{Y} \times \mathrm{N}$ :

$\begin{array}{llrl}\text { (a) } & \text { Parents } & 5 & 0.073^{*} \\ \text { Remainder } & 9 & 0.015 \\ \text { Pa) } & 5 & 0.007 \\ & \text { Remainder } & 10 & 0.002\end{array}$

of change throughout the entire range of environments covered by this experiment. However, this conclusion may not be strictly correct, as evidence presented elsewhere indicates that the error item used for testing departures from linearity has been obtained by pooling heterogeneous variances. Consequently, in order to investigate the constancy of these linear regressions, each of the four treatment combinations of years and nitrogen levels, which individually occupy different parts of the environmental spectrum, has been analysed separately (tables $6 a$ and $b$ ). It will now be seen that the regression slopes change between these four environmental combinations, as evidenced by the significance of the heterogeneity item of table $6 a$, which in turn reflects the considerable narrowing of the response range manifested under the more limiting conditions of low nitrogen (table $6 b$ ). Such alterations could denote either an absolute change in response from one treatment to another, or they could represent a degree of curvilinearity. Unfortunately, the results obtained in this experiment do not permit us to discriminate between these two hypotheses. Nevertheless, it should be pointed out that, when the complete range of environments are 
being considered, the overall regression lines retain considerable predictive value since the heterogeneity mean square is highly significant when tested against the residual mean square (Perkins and Jinks, 1968a; Samuel et al., loc. cit.). However, because of the apparent change in slope between the two nitrogen regimes, it was decided to carry out the genetic analysis on the response regressions calculated separately for each treatment.

In view of the high correlation between mean and response it is not surprising that the results of this analysis shown in table 7 indicate that the pattern of inheritance for response closely parallels the one previously described for yield, being controlled by genes whose effects are largely additive in action. There is little evidence for either dominance or epistasis,

TABLE 8

Test for homogeneity of regression residual and within environmental mean squares for the three groups, New Zealand (N.Z.), indigenous $(I)$ and New Zealand $\times$ indigenous $(\mathcal{N} . Z . \times I)$. Parenthetical subscripts indicate the degrees of freedom upon which the $\chi^{2}$ tests are based

\begin{tabular}{|c|c|c|c|c|c|c|}
\hline Character & \multicolumn{3}{|c|}{$\begin{array}{l}\text { Regression residual } \\
\text { mean square }\end{array}$} & \multicolumn{3}{|c|}{$\begin{array}{l}\text { Within environmental } \\
\text { mean square }\end{array}$} \\
\hline Group & N.Z. & I & N.Z. $\times$ I & N.Z. & I & N.Z. $\times$ I \\
\hline $\begin{array}{l}\text { Within group } \\
\text { variance }\end{array}$ & 37.9 & $66 \cdot 9$ & $27 \cdot 5$ & 33.0 & $62 \cdot 4$ & $54 \cdot 8$ \\
\hline $\begin{array}{l}\text { Within group } \\
\text { heterogeneity }\end{array}$ & $13 \cdot 8_{[5]}^{*}$ & $7 \cdot 1_{[5]}$ & $38 \cdot 1_{[17]}^{* *}$ & $24 \cdot 2_{[5]}^{* * *}$ & $24 \cdot 9 * * *$ & $134 \cdot 2_{[17]}^{* * *}$ \\
\hline $\begin{array}{l}\text { Between group } \\
\text { heterogeneity }\end{array}$ & & $52 \cdot 5_{[2]}^{* *}$ & & & $157 \cdot 5_{[2]}^{* * *}$ & \\
\hline
\end{tabular}

though clearly there is a significant interaction with nitrogen levels which again reflects the change in slope from poor to good environments.

By analysing the data in this way it has been possible to divorce the response patterns of these families to regular cutting treatments from their response to other environmental factors. Since the responses change significantly between both years and nitrogen levels, it may be concluded that the environmental treatments imposed in this experiment affect the families differently. This is in contrast to the results obtained by Breese (loc. cit.) who discovered that the overall response of certain populations of cocksfoot (Dactylis glomerata) was the same for all factors considered (e.g. cutting treatments, locations and years).

So far only mean and response of the four phenotypic components of yield have been examined in any detail. In order to complete this picture, however, it is necessary to investigate the two remaining components, namely stability and within environmental variance.

\section{(d) Stability and within environmental variance}

Initially these two characters were analysed at the family level by the genetic analysis presented earlier (Yates, loc. cit.). No clear-cut pattern of inheritance emerges for these characters, whilst overall they are correlated neither with each other nor with the mean and regression coefficient. However, this is by no means the whole story, because if the geographic origins of the material are taken into account, certain interesting features come to light. Considering stability first, it is evident from table 8 that the New 
Zealand group is more stable than the indigenous material, whilst crosses between them prove to be the most stable of all. A Bartlett's test for homogeneity of variances reveals that these group differences are highly significant. But the results within each group are even more illuminating because all the families within the two parental groups are either uniformly stable (New Zealand) or unstable (indigenous), whereas families within the hybrid group display a much wider range of variability as evidenced by its higher $\chi^{2}$ value. Clearly these results illustrate two different facets of this character, namely stability per se and its variability, which in this material at least are inversely related.

Turning to the within environmental variance, a somewhat analogous situation arises here, with New Zealand material exhibiting a lower variance than the indigenous material, though the hybrid group now occupies an intermediate position. Again a Barlett's test discloses highly significant between group differences, but similar differences also occur within all three groups. Even so, it is clear that the hybrid group is considerably more heterogeneous than either of the two parental groups. Thus, although the original analysis failed to detect any genetic control for either of these characters, nevertheless a regrouping of the families revealed genetically based differences which can be related to the geographic origin of the parents.

\section{Discussion}

In discussing these results it is important to bear in mind the structure of this experiment. Yield data were obtained from material which was harvested at regular intervals over a period of two years and grown under two contrasting nitrogen regimes. From the original analysis it appeared that all the genotype-environment interactions present in this material could be satisfactorily explained in terms of differences between linear response regressions which covered the entire range of environments encountered in this experiment. However, when the environmental spectrum was subdivided into its component parts it became evident that small but significant changes in slope occurred from year to year and between the two nitrogen levels. Such changes could indicate curvature of the response lines, as discussed by Samuel et al. (loc. cit.) or, alternatively, it could be that factors such as light and temperature, which affect response within years, are operating at an entirely different level from those affecting response across nitrogen levels or from one year to the next. As mentioned earlier, this is in contrast to the results obtained by Breese (loc. cit.) and it is pertinent, therefore, to examine these findings in relation to the selective history of the parental genotypes of S. 24 .

During the development of this cultivar, emphasis was placed primarily upon yield at the conservation stage, although due consideration was of course given to production at other times of the year. Thus the aim was to combine high annual yield with a particular pattern of growth within a year. The presence of a high correlation between mean and resposne indicates that selection has for the most part been successful. But more than this it appears to have bestowed upon this cultivar the ability to adapt itself not only to such general environmental factors as soil nitrogen but also to the more specific conditions which prevail within a year.

From the present results it would be difficult to study the physiology of 
these differential responses in any detail. Nevertheless it would be of interest to investigate more fully the evidence for both general and specific response patterns to a number of environmental agencies. When such patterns are more clearly established it may then be possible to inquire into the significance of these phenomena.

In view of the high correlation between mean and response in this material, it was anticipated that their genetic control would be identical. This in fact proved to be so, with both characters being mediated by genes whose effects were largely additive. Again this contrasts with the results of Breese (loc. cit.), where there was neither a correlation between mean and response nor any similarity in their genetic control. The existence of such a high correlation in this cultivar has important connotations for its future development because it signifies that further increases in yield can be attained by selecting for an increased expression of either of these two phenotypic components. Similar correlations have also been discovered for both flowering time (Hill and Perkins, loc. cit.) and final height (Perkins and Jinks, 1968a) in Nicotiana rustica, although for the latter there is evidence to suggest that the correlation can be broken.

These results add to the growing body of evidence which indicates that genotype-environment interactions can be related to the environment in a simple, linear fashion, thereby lending a measure of predictability to a previously unpredictable situation. In herbage breeding, where an already difficult position is aggravated by the knowledge that a grass or legume cultivar will experience marked environmental changes during its productive life, such relationships could be of paramount importance. Thus the detection of similar relationships amongst highly selected material in this experiment coupled with the findings of Samuel et al. (loc. cit.) and Breese (loc. cit.) provide a powerful demonstration of the role which this analytical approach could play in practical breeding and selection programmes. Certainly further research is needed before the true value of these regressional techniques can be appraised, but their future impact upon plant breeding in general, and herbage breeding in particular, is likely to be very considerable.

\section{SUMmary}

I. It has recently become apparent that linear regression techniques can reduce the problems posed by genotype-environment interactions to more manageable proportions.

2. This analytical approach has been applied to a diallel cross without selfs between six of the genotypes which comprise the basic plant material of the S. 24 cultivar of perennial ryegrass (Lolium perenne).

3. An analysis of forage yield over a range of environments provided by successive cuts in two years at high and low levels of applied nitrogen discloses highly significant differences between families, whilst of the environmental treatments the effect of nitrogen is the most pronounced. Analysis also reveals that the families interact with the various environmental factors.

4. A highly significant proportion of these interactions can be attributed to differences between the linear response of the families to the range of environments encountered here. Moreover at this stage no significant departures from linearity could be detected amongst these responses. 
5. Annual yield and linear response are positively correlated. Not surprisingly, therefore, the inheritance of these characters proves to be similar, being controlled chiefly by additive differences between parents, although environmental factors, especially level of nitrogen, figure prominently in the expression of both yield and response.

6. The fact that the overall analysis discloses no significant departures from linearity in the response of this material, even though it was shown subsequently that the expression of this character depended upon the environment, emphasises the need for caution when applying these techniques to experimental data.

7. A genetic analysis of the remaining two phenotypic components, stability and within environmental variance, reveals no clear-cut pattern of inheritance at the family level. However, when this material is grouped according to its geographic origin, then families derived from parents of New Zealand origin have on average a lower expression than families from indigenous parents for these characters, whilst, except for stability, families of mixed ancestry are intermediate.

8. These results are discussed specifically in relation to the past selection history of S. 24, although some of the more general implications of these results are briefly outlined.

Acknowledgments.-We are indebted to Dr E. L. Breese for his helpful advice and criticism and to Professor P. T. Thomas, C.B.E., for his interest in this work. One of the authors (C. J. A. S.) acknowledges the financial support of the Science Research Council.

\section{REFERENCES}

BREESE, E. L. 1969. The measurement and significance of genotype-environment interactions in grasses. Heredity, Lond., 24, 27-44.

BUCIO ALANIS, L. 1966. Environmental and genotype-environmental components of variability. I. Inbred lines. Heredity, Lond., 21, 387-397.

BUCIO ALANTS, L., AND HILL., J. 1966. Environmental and genotype-environmental components of variability. II. Heterozygotes. Heredity, Lond., 21, 399-405.

COMSTOCK, R. E., AND ROBINSON, H. F. 1952. Genetic parameters, their estimation and significance. Proc. Sixth Int. Grassld Congr., 284-291.

EBERHART, s. A., AND RUSSELL, w. A. 1966. Stability parameters for comparing varieties. Crop Sci., 6, 36-40.

FINLAY, K. W., AND WILKINSON, G. N. 1963. The analysis of adaptation in a plant breeding programme. Aust. F. Agric. Res., 14, 742-754.

FREEMAN, G. H., AND PERKINS, JEAN M. 1971. Environmental and genotype-environmental components of variability. VIII. Relations between genotypes grown in different environments and measures of these environments. Heredity, Lond., 26 (in the press).

HANSON, C. H., ROBINSON, H. F., AND COMSTOCK, R. E. 1956. Biometrical studies of yield in segregating populations of Korean Lespedeza. Agron. Four., 48, 268-272.

HILL, J., AND PERKINS, JEAN M. 1969. The environmental induction of heritable changes in Nicotiana rustica. Effects of genotype-environmental interactions. Genetics, 61, 661-675.

JEnkin, T. J. 1943. Aberystwyth strains of grasses and clovers. Agriculture, Lond., 50, 343349.

PERKINS, JEAN M., AND JINKS, J. L. 1968a. Environmental and genotype-environmental components of variability. III. Multiple lines and crosses. Heredity, Lond., 23, 339-356.

PERKINS, JEAN M., AND JINKS, J. L. 1968 $b$. Environmental and genotype-environmental components of variability. IV. Non-linear interactions for multiple inbred lines. Heredity, Lond., 23, 525-535. 
SAMUel, C. J. A., Hill, J., BREese, E. L., AND DAvies, Alison. 1970. Assessing and predicting environmental response in Lolium perenne. 7. agric. Sci., Camb., 75, 1-9.

YATES, F. 1947. Analysis of data from all possible reciprocal crosses between a set of parental lines. Heredity, Lond., 1, 287-301.

yATES, F., AND COCHRAN, w. G. 1938. The analysis of groups of experiments. 7. agric. Sci., Camb., 28, 556-580. 